\title{
Pre-concentration of Pesticide Residues in Environmental Water Samples Using Silica Nanoparticles and Identification of Residues By GC-MS Method
}

\author{
TENTU. NAGESWARA RAO ${ }^{1 *}$, A. MURALIDHAR REDDY², \\ SNVS. MURTHY ${ }^{3}$, PRATHIPATI REVATHI ${ }^{1}$ and K. SUNEEL KUMAR ${ }^{4}$
}

\author{
${ }^{1}$ Department of Chemistry, Krishna University, Machilipatnam, Andhra Pradesh, India. \\ ${ }^{2}$ Department of Chemistry, SKVP\&Dr.K.S Raju Arts and Science College, Penugonda, AP, India. \\ ${ }^{3}$ Department of Organic Chemistry, D.L.R. P.G. College, Gollalamamidada, AP, India. \\ ${ }^{4}$ Techno Global University, Shillong, Maghalaya, India. \\ *Corresponding author E-mail : tentu6581@ rediffmail.com
}

http://dx.doi.org/10.13005/ojc/320454

(Received: July 27, 2016; Accepted: August 22, 2016)

\begin{abstract}
The silica nanoparticles prepared by stober's mechanism by reaction of tetraethylorthosilicate (TEOS) with ammonia was tested for their adsorption capacity in the pre-concentration of residues of pesticides in water. The synthesized nanoparticles were characterized by Scanning Electron Microscope (SEM), Transmission Electron Microscope (TEM) and X-Ray Diffraction (XRD). The size of the silica nanoparticles were 50 to $250 \mathrm{~nm}$. The solid phase extraction (SPE) cartridges were prepared by filling the empty cartridges of $5.5 \mathrm{~cm}$ length and $0.3 \mathrm{~cm}$ i.d. with $200 \mathrm{mg}$ of nanoparticles and protected between two polytetrafluroethylene (PTFE) frits. To avoid the passage of nanoparticles, $2 \%$ solution of polystyrene in chloroform was passed through PTFE frits and dried in air for two hours at room temperature before fitted into the cartridges. This process is to reduce the pore size of the PTFE frits. These cartridges are used in pre-concentration of different types of residues of pesticides in water. The pyrethroids tested for the pre-concentration are tetramethrin, lambda-cyhalothrin, cyphenothrin. The water samples were spiked with aliquots of pesticides and were passed through the cartridges. The amounts of the pesticides adsorbed on the cartridges were tested. The influence of temperature, sample volume, flow rate, $\mathrm{pH}$ and ionic strength on the performance of the cartridges was checked. The results of fortified sample analysis were compared with the data obtained from the commercially available $\mathrm{C} 18$ cartridges for the sample volume. The separation parameters were established for the simultaneous determination of residues using GC-EI-MS. The method was validated by means of linearity, precision, and assay accuracy. The limit of detection (LOD) and the limit of quantification (LOQ) were established based on the signal to noise ratio $3: 1$ and 10:1 respectively. An analytical method for the enrichment of residues using nanoparticles based SPE cartridges were developed and factors influencing the pre-concentration of residues of pyrethroids were studied and reported.
\end{abstract}

Keywords: Silica nanoparticles, Pyrethroids, Solid phase extraction, GC-EI-MS. 


\section{INTRODUCTION}

Nanotechnology is an interdisciplinary area of research involving chemistry and physics which is growing rapidly for the past one decade. Nanoparticles have taken a key role in developing new drugs and pharmaceuticals for their smart delivery in selected tissue and organism. The widespread use of nanoparticles raised the eyebrows of many scientists to utilize their versatile applications in the field of aeronautics, agriculture environmental and health science ${ }^{1}$. The advantage of nanoparticles over other material is their smaller size and greater availability of surface area and lighter in weight. In the field of environmental science several nano catalysts $^{2}$ are employed for the pre-concentration and selective decontamination of carcinogenic compounds. The residues of xenobiotics such as pesticides and relevant molecules which are likely to present in trace quantities have greater influence on the environment and human health ${ }^{3}$. The fate of pesticides used in the field depends on its properties such as evaporation; persistence, adsorption, leaching etc., and the presence of residues of pesticides contribute to the environmental water pollution mainly due to leaching and runoff ${ }^{4}$. Ground water is the most important source of drinking water; the accumulation of residues in the water reservoirs and other sources of water have direct effect not only on human population but also on aquatic organism ${ }^{5}$. Many pesticides have been shown to cause adverse effect in spite of their presence in trace quantities. To protect the environment from the toxic contaminants, several monitoring techniques are being employed. Continuous monitoring and the remedial measures are necessary to maintain the ecological balance in providing the human habitants a sustainable and safe living environment. In this process of modernization, the help of new techniques and technology has been derived to find for the new challenges. To detect the residues at nano and pico gram level it is necessary to enrich the residues from the bulk sample before subjected to the instrumentation techniques. Liquid - Liquid extraction is one method being used for the pre-concentration of residues past several decades ${ }^{6}$. Solid phase extraction (SPE) is the next development in enrichment of residues. The restrictions in use of organic solvent and their consumption in larger quantity have lead to the development of SPE techniques which is a simple solvent free technique.
The SPE methods have become versatile due to the high adsorption capacity of the sorbent used and the preconcentration capacity of residues at nano gram level present in huge quantity of sample matrix. Nanoparticles are well known for the adsorption of many contaminants Solid phase extraction (SPE) is one such technique used widely for monitoring the environmental contaminations by enrichment of residues from the environmental substrates mainly from the aquatic strata ${ }^{7-8}$. This technique has the strength to quantify the environmental samples in larger quantity in a short span of time and does only limited resources. The residues present in several liters of water samples can be pre-concentrated within a small tiny cartridges subsequently can be eluted using small quantities of solvent for their estimation, minimizing the use of larger quantities of solvents. This process has the direct contribution to maintain sustainable clean and green environment apart from saving the money and time in doing such a critical analysis. The pre-concentration of residues of different type herbicides in water and at different $\mathrm{pH}$ conditions using nanoparticles based SPE cartridges ${ }^{9}$. Nanoparticles are well known for the adsorption of many contaminants in water due to their high surface area. Alumina, Carbon ${ }^{10-}$ 11 and Silica particles are identified as well-known adsorbents. In recent years researchers discovered the capacity of nanoparticles in adsorbing many organic and inorganic contaminants present in the environmental substrates ${ }^{12-13}$ however still this need to be established applied for several such molecules. In view of the paucity of information, present study was conducted to investigate the capacity of silica nanoparticles as solid phase adsorbent in the preconcentration of residues of pesticides. The lists of pyrethroids studied were tetramethrin, lambdacyhalothrin, cyphenothrin. An analytical method was developed for the simultaneous determination of residues of pyrethroids using Liquid chromatography electro spray tandem mass spectrometry (GC-EI$\mathrm{MS})$.

\section{MATERIALS AND METHODS}

Reference analytical standard of tetramethrin (purity 99.1\%), cyhalothrin $\mathrm{n}$ (purity 99.6\%) and cyphenothrin (purity 98.9\%) were obtained from Sigma Aldrich. Tetraethylorthosilicate, Acetonitrile, Water HPLC grade, ammonia solution AR grade, 
and formic acid AR grade were obtained from the Merck India limited. Distilled water was purified by using the Milli-Q Plus apparatus (Millipore, Bedford, MA, USA). The environmental water samples were collected from different irrigation wells in Medak District, Telangana, India.

\section{Preparation of silica nanoparticles}

Silica nanoparticles were synthesized following the method described by Stober. Tetraethylorthosilicate $(0.1 \mathrm{ml})$ was dissolved in $10 \mathrm{ml}$ of methanol and kept undisturbed at $\sim 1^{\circ} \mathrm{C}$ for thirty minutes. To this solution $5 \mathrm{ml}$ of $28 \%$ ammonium hydroxide solution was added drop wise. The contents were sonicated for 2 hours in floating ice bath. While sonication, slow formation of white precipitate can be seen. The resulting white precipitate at the end of two hour sonication was washed several times with milli $Q$ water followed by methanol to remove the excess of ammonium hydroxide. The precipitate thus purified was centrifuged using a cooling centrifuge at $10^{\circ} \mathrm{C}$ and $7500 \mathrm{rpm}$. Collected the precipitate of silica nanoparticles by decanting the solvent and dried under nitrogen atmosphere in a desiccator.

\section{Preparation of solid phase extraction cartridges (SPE) using nanoparticles}

Two different SPE cartridges were prepared by filling the empty cartridges of size $0.3 \mathrm{~mm}$ i.d. and
$5.5 \mathrm{~cm}$ length silica nanoparticles. The material was packed in between two PTFE frits. The normal pore sizes of these PTFE frits were found to be $0.2 \mathrm{i}$, which is higher than the particle size of silica nanoparticles. To avoid the passage of nanoparticles, $2 \%$ solution of polystyrene in chloroform was passed through PTFE frits and dried in air for two hours at room temperature before fitted into the cartridges. This process is to reduce the pore size of the PTFE frits. The nanoparticles each $200 \mathrm{mg}$ were packed in to the separate cartridges. The packed cartridges were conditioned with $10 \mathrm{ml}$ of methanol, followed by $20 \mathrm{ml}$ of milli $Q$ water to remove the soluble impurities if any present in the cartridges. The conditioned cartridges thus prepared were used for the pre concentration of potential toxic pesticide residues present in water.

\section{Preparation of Standard stock solutions}

The stock solutions of reference analytical standards were prepared by weighing about $10 \mathrm{mg}$ of respective herbicide of known purity in different $20 \mathrm{ml}$ volumetric flasks using an analytical balance having accuracy of $0.01 \mathrm{mg}$. The content of each flask were dissolved using HPLC grade acetone and made up to the mark. A secondary stock solution was prepared in $20 \mathrm{~mL}$ volumetric flask by mixing the stock solutions together in appropriate volumes using micro micropipette and made up to the mark with acetonitrile.

Table 1: Details of the calibration solutions used for the construction of linear graphs

\begin{tabular}{lll}
\hline S. No. & Pyrethroids & Concentrations in $\mathbf{n g} / \mathbf{m L}$ \\
\hline 1 & Tetramethrin & $0.05,0.1,2.0,5.0,10.0,50.0 \& 100.0$ \\
2 & Lambda-cyhalothrin & $0.05,0.1,2.0,5.0,10.0,50.0 \& 100.0$ \\
3 & Cyphenothrin & $0.05,0.1,2.0,5.0,10.0,50.0 \& 100.0$ \\
\hline
\end{tabular}

Table 2: The details of linear calibration range, Limit of detection, Fragment ions used in MRM mode for different pyrethroids

\begin{tabular}{lcccccc}
\hline Pyrethroids & $\begin{array}{c}\text { Retention } \\
\text { time } \\
(\mathbf{m i n})\end{array}$ & $\begin{array}{c}\text { Linearity } \\
\text { range } \\
\mathbf{( n g / m L})\end{array}$ & $\mathbf{R 2}$ & $\begin{array}{c}\text { LOD } \\
\mathbf{( n g / m L})\end{array}$ & $\begin{array}{c}\text { Molecular } \\
\text { mass }(\mathbf{m} / \mathbf{Z})\end{array}$ & $\begin{array}{c}\text { Fragment } \\
\text { ions }(\mathbf{m} / \mathbf{Z}) \text { used } \\
\text { for Quantification }\end{array}$ \\
\hline Tetramethrin & 7.9 & $0.05-100$ & 0.9995 & 0.05 & 331 & 164,123 \\
Lambda-cyhalothrin & 9.5 & $0.05-100$ & 0.9998 & 0.05 & 449 & 181,197 \\
Cyphenothrin & 10.5 & $0.05-100$ & 0.9999 & 0.05 & 375 & 123,181 \\
\hline
\end{tabular}




\section{Preparation of calibration solutions}

The secondary stock solution thus prepared was diluted serially using HPLC grade acetone to give the calibration solutions. The linearity of the method was studied by analyzing standard solutions of at least six different concentrations in the range

Table 3: Average recovery of herbicide residues using nanoparticles based SPE cartridges

\begin{tabular}{|c|c|c|}
\hline \multirow[t]{2}{*}{ Pyrethroids } & \multicolumn{2}{|c|}{$\begin{array}{c}\text { Recovery \% in } \\
\text { Silica nanoparticles }\end{array}$} \\
\hline & $0.05 \mu \mathrm{g} / \mathrm{mL}$ & $0.5 \mu \mathrm{g} / \mathrm{mL}$ \\
\hline Tetramethrin & 83 & 90 \\
\hline Lambda-cyhalothrin & 85 & 92 \\
\hline Cyphenothrin & 84 & 94 \\
\hline
\end{tabular}

from 0.005 to $200 \mathrm{ng} / \mathrm{mL}$. Presented the details of calibration solutions for the construction of linear graph in Table 1.

\section{EXPERIMENTAL}

GC-EI-MS conditions for the determination and confirmation of residues of pyrethroids

The configuration of GC-MS system used includes a (Agilent/ 6890N) gas chromatograph coupled with 5975C Mass-Selective Detection (MSD) and Chemstation software, the detector was set in selective ion monitoring mode (EI) mode. The peaks separation were obtained on a DB-1 capillary column (30 m length, $0.25 \mathrm{~mm}$ internal diameter, $0.25 \mu \mathrm{m}$ film thickness). The injection system was operated in split mode with a split ratio of 10:1. The injector and the transfer line temperatures were $295^{\circ} \mathrm{C}$ and $300^{\circ} \mathrm{C}$, respectively. column oven temperature was programmedfrom $100^{\circ} \mathrm{C}$ for 3 minutes, increased

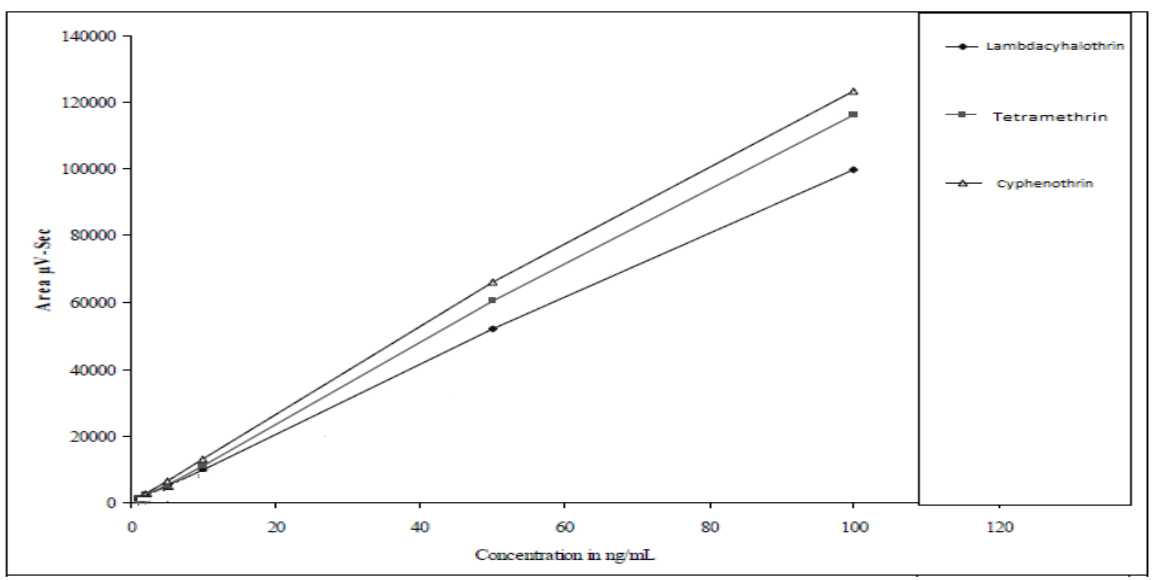

Fig. 1: Calibration of pyrethroids using GC-EI-MS

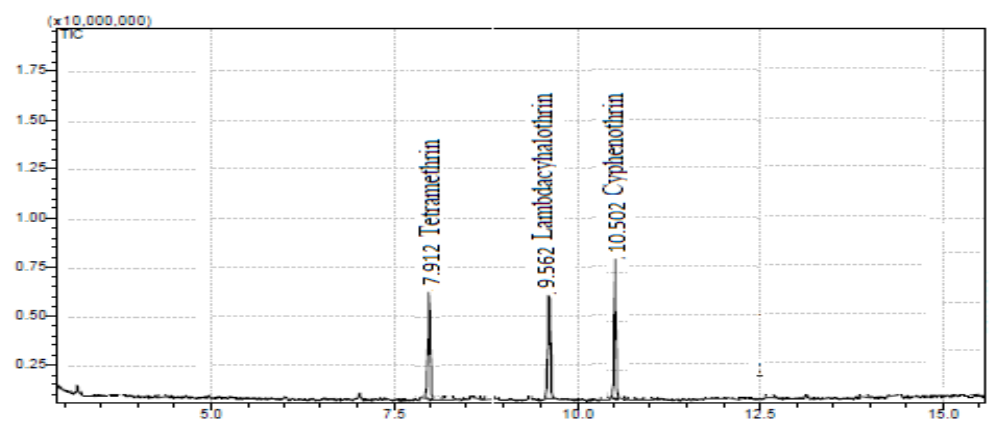

Fig. 2: Representative GC-EI-MS total ion chromatogram recovery of pyrethroids by using silica nanoparticles cartridge 
at $10^{\circ} \mathrm{C}$ to $290^{\circ} \mathrm{C}$. The carrier gas used was helium (GC grade) at a flow rate of $1.0 \mathrm{ml} / \mathrm{min}$ and the sample volume injected onto the column was 1.0 $\mu \mathrm{L}$. A Agilent Chemstation Software was used for acquisition of data and calculation of peak areas. The retention time of tetramethrin, lambda-cyhalothrin, cyphenothrin were about $7.9 \mathrm{~min}, 9.5$ and $10.5 \mathrm{~min}$ and the total time of chromatographic analysis was $8.0 \mathrm{~min}$.

\section{Preparation of calibration curves}

A calibration curve was plotted between concentrations of standard solutioninjected and peak area observed (Figure. 1). The LOD was
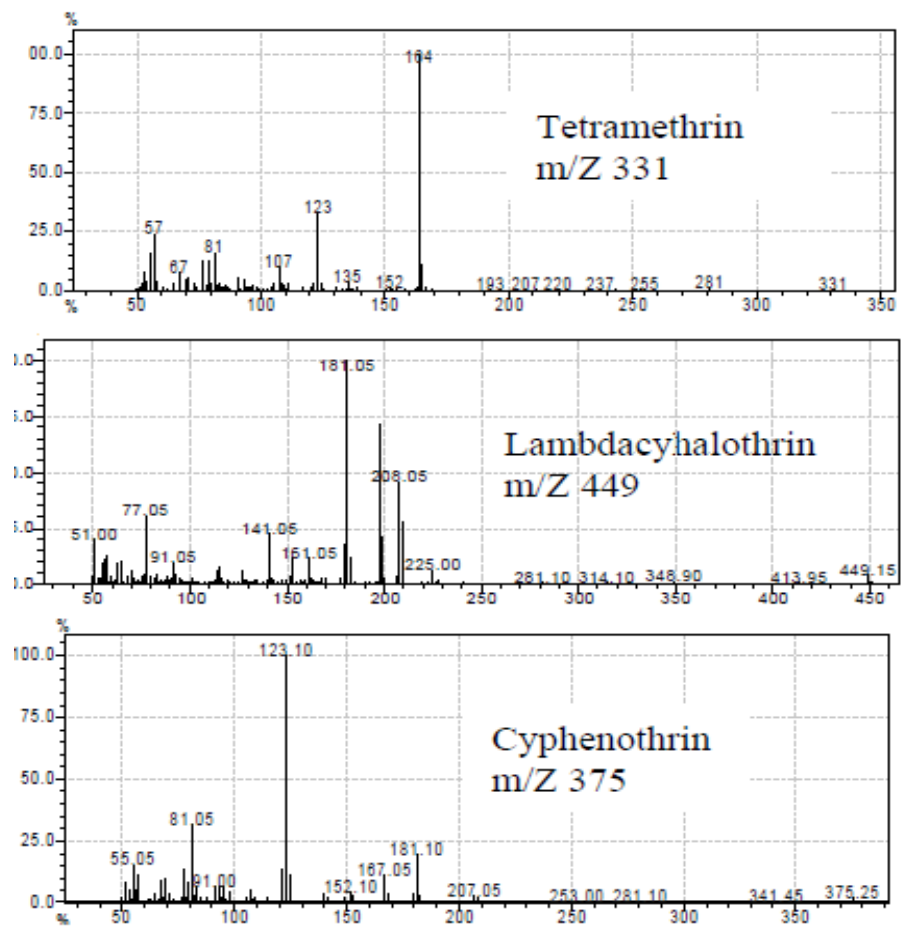

Fig. 3: GC-EI -MS mass spectra of pyrethroids

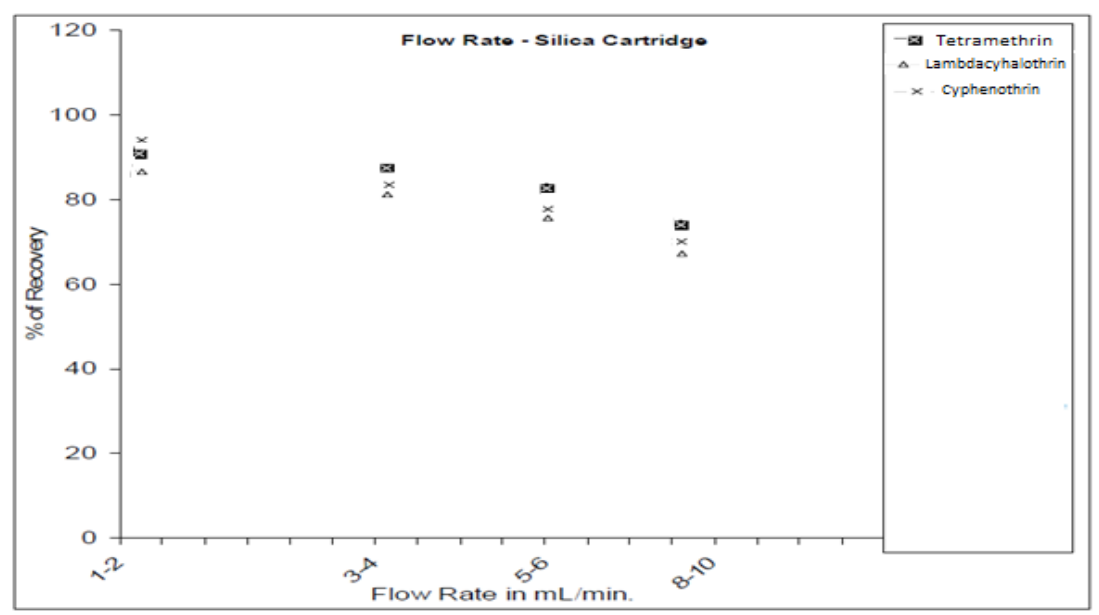

Fig. 4: Effect of flow rate in pre-concentration of pyrethroid residues 
established based on thesignal to noise ratio $3: 1$. No peak overlapping was observed while quantifying theresidues of pyrethroids using this method. All the residues of pyrethroids are presented with an abundant molecular ion peak. Residues were quantified using the molecular ion peak fragments. At least two molecular ion fragments were used for quantification of pyrethroid residues in water. The details regarding the limit of detection by GC-MS, retention time, molecular mass, fragmentation ions used for quantification of residues were presented in Table 2.

\section{Assay accuracy and repeatability}

The assay accuracy of the method was evaluated by spiking two different concentrations 0.05 and $0.5 \mathrm{ng} / \mathrm{mL}$ of herbicide mixture in $500 \mathrm{~mL}$ of milli $Q$ water. The repeatability of the method was determined by analyzing six replicate samples at each concentration level along with two controls for

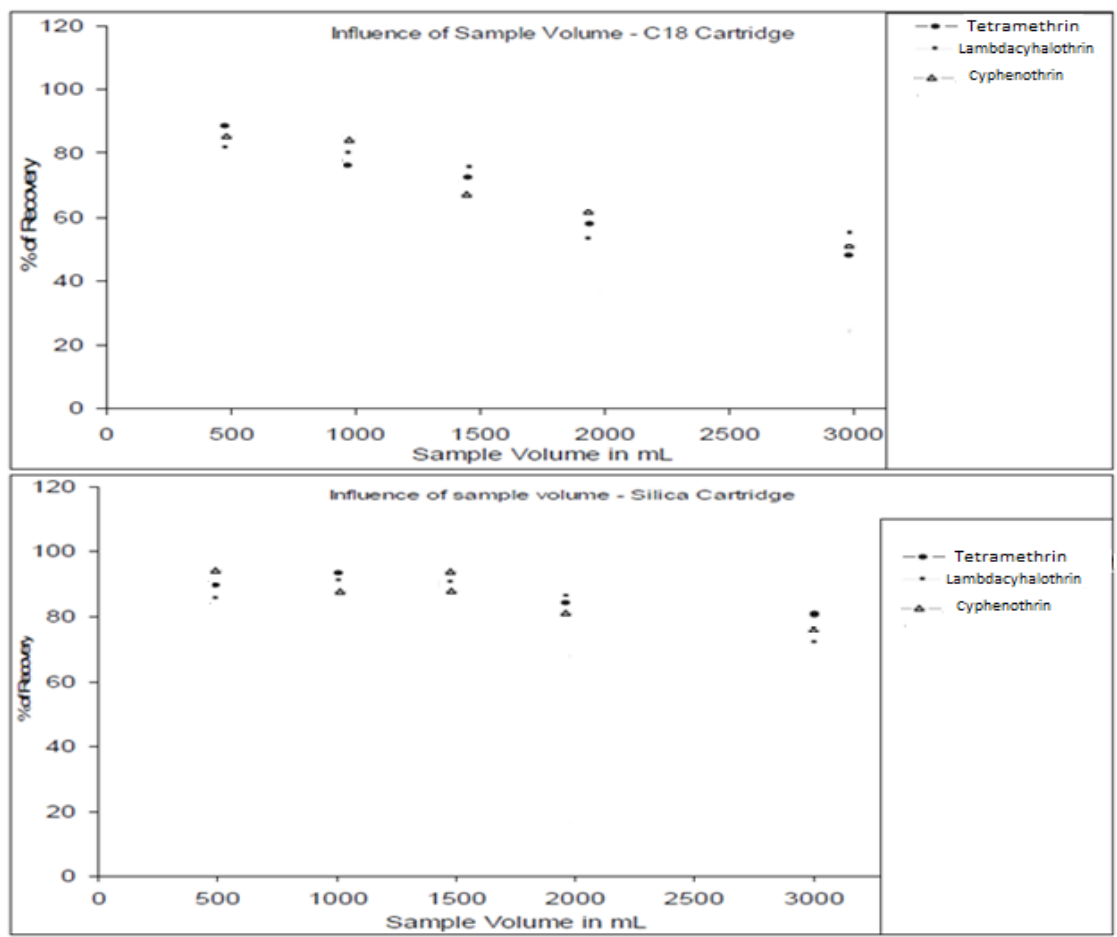

Fig. 5: Effect of sample volume in pre-concentration of pyrethroid residues

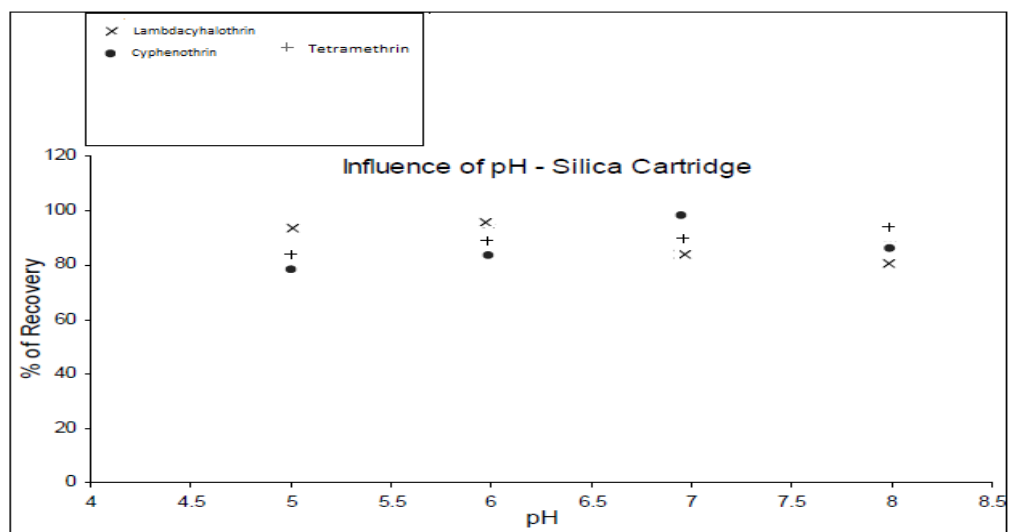

Fig. 6: Effect of $\mathrm{pH}$ in pre-concentration of herbicide residues 


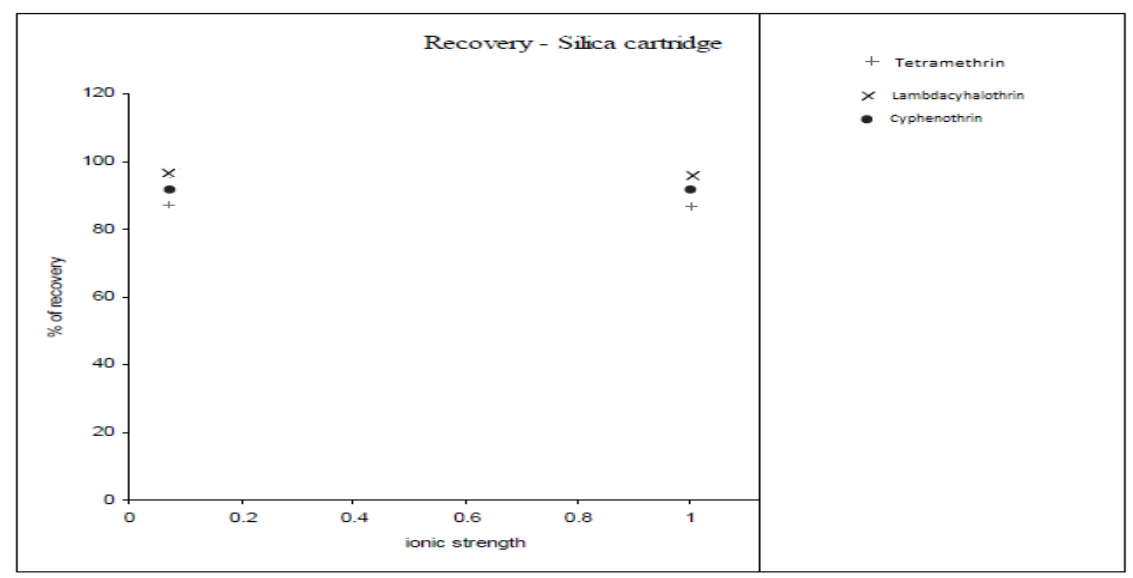

Fig. 7: Influence of ionic strength in pre-concentration of pyrethroid residues

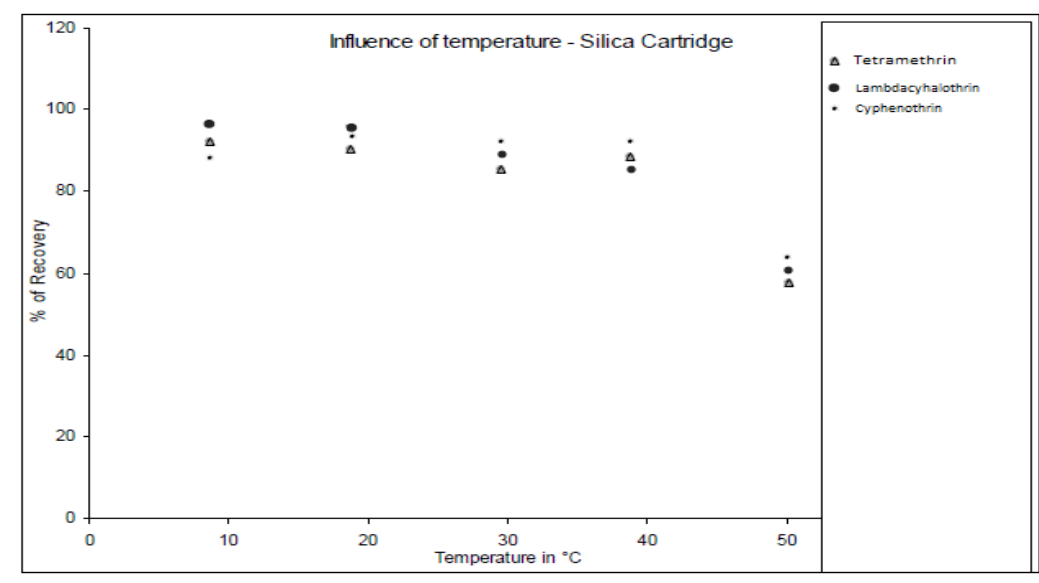

Fig. 8: Effect of temperature in pre-concentration of pyrethroid residues

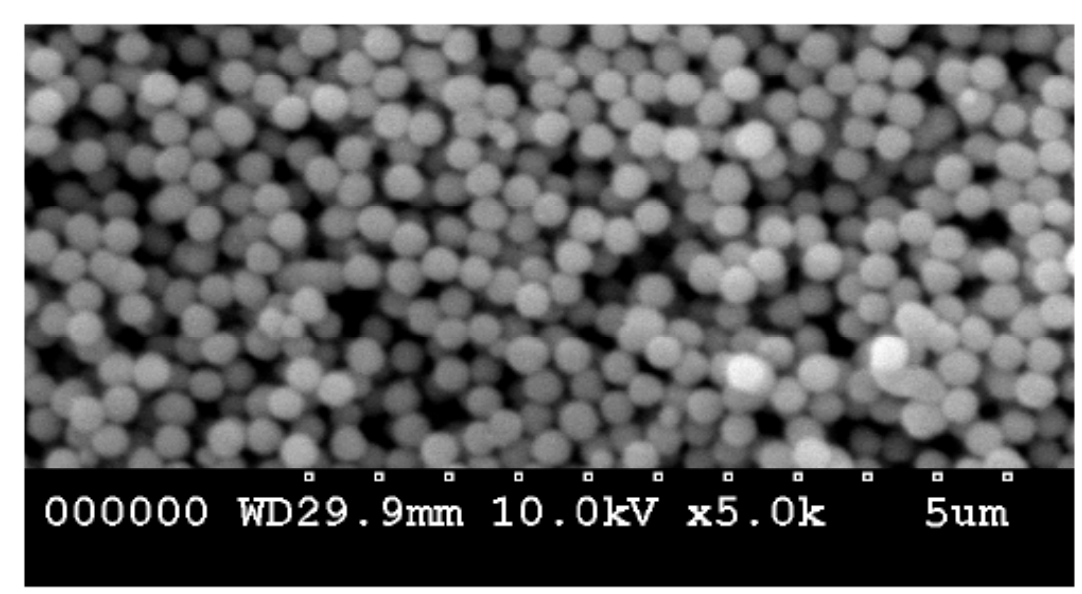

Fig. 9: Scanning Electron Microscope image of Silica nanoparticles 
the identification of interferences. The concentration of the solvent present in the spiked water sample was not exceeded $0.1 \%$. After spiking, the water samples were mixed thoroughly, equilibrated and maintained at $20+2^{\circ} \mathrm{C}$ in temperature controlled water bath and passed through the cartridges by means of suction with flow rate 3 to $4 \mathrm{ml}$ per minute. The cartridges were dried under vacuum and residues were then eluted using $5 \mathrm{ml}$ of HPLC grade acetone. Based on the recovery percentage the limit of quantification was established. The average recovery percentage for each pyrethroid in milli $Q$ water was presented in Table 3. The representative GC-EI-MS total ion chromatogram of recovery sample is presented in Figure 2 and GC-El-MS spectra for each compound were presented in Figure 3.

\section{Effect of flow rate}

The influence of flow rate in pre-concentration of residues was checked by conducting recovery study at flow rates 1-2 mL, 3-4 mL, 5-6 mL and 8-10 $\mathrm{mL} / \mathrm{min}$. The flow rates were controlled using vacuum attached to SPE manifold. At these flow rates, 0.1 $\mu \mathrm{g} / \mathrm{mL}$ concentration level of samples were passed through the cartridges and quantified the adsorbed residues in the cartridges by eluting the residues with acetonitrile. Presented the results graphically in Figure 4.

\section{Analysis of pre-concentration capacity of SPE cartridges - influence of sample volume}

The efficiency of cartridges was tested with different sample volumes from $500 \mathrm{~mL}$ to 3000 $\mathrm{mL}$. The efficiency of these nanoparticles based

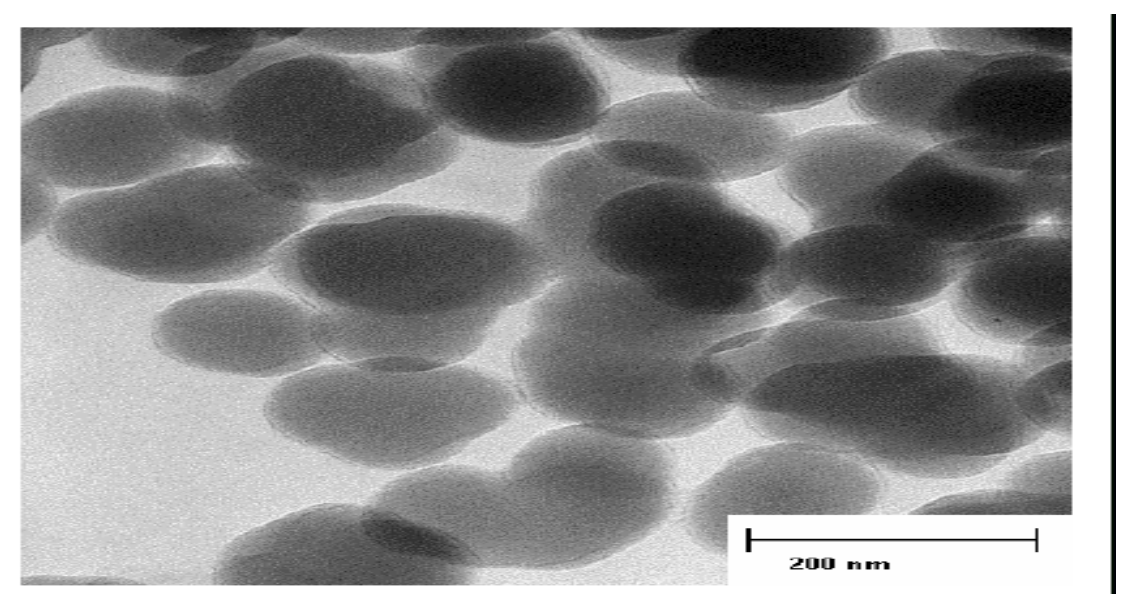

Fig. 10: Transmission Electron Microscope image of Silica nanoparticles

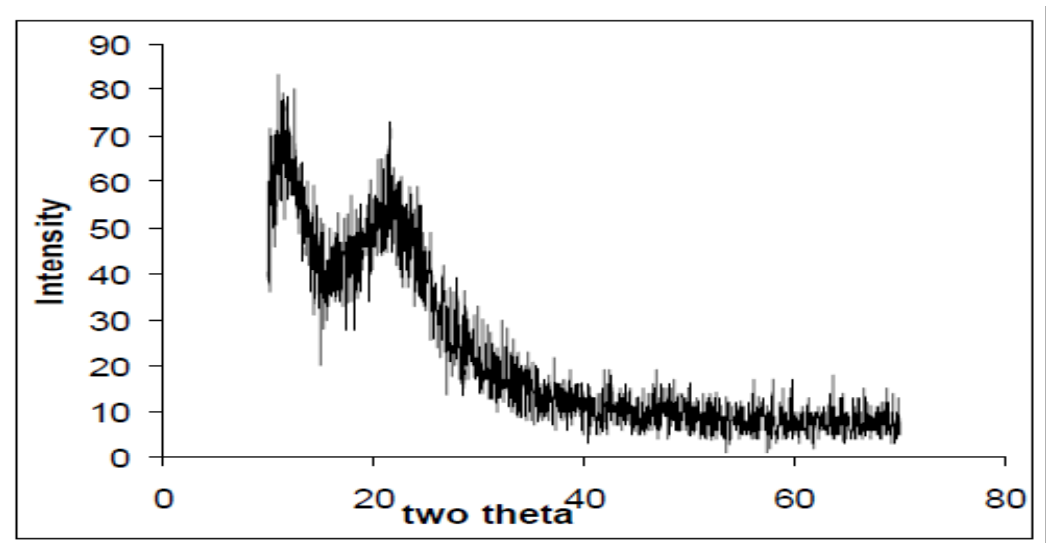

Fig. 11: XRD patterns of Silica nanoparticles 
cartridges was compared with conventional C18 cartridges. The results are presented graphically in Figure 5.

\section{Effect of $\mathrm{pH}$, ionic strength and temperature}

The influence of $\mathrm{pH}$ in pre-concentration of residues was investigated by adjusting $\mathrm{pH}$ of the water samples using $0.1 \%$ hydrochloric acid and $0.1 \%$ sodium hydroxide solutions. After adjusting the desired $\mathrm{pH}$, spiked the water samples at 0.01 and $0.1 \mathrm{ng} / \mathrm{mL}$ levels of herbicide mixture. The spiked sample $(500 \mathrm{~mL})$ was passed through the cartridges. During this experiment the temperature of the water was maintained at $20+2^{\circ} \mathrm{C}$. The experiment was carried out at four different $\mathrm{pH}$ levels 5, 6, 7, and 8 . The influence of $\mathrm{pH}$ in pre-concentration of herbicide residues was presented graphically in Figure 6. The effect of ionic strength was checked by spiking the residues of pyrethroids in $0.1 \%$ and $1 \%$ sodium chloride solution in distilled water at 20 $+2^{\circ} \mathrm{C}$. The influence of ionic strength in the preconcentration of residues using nanoparticles based cartridges was presented graphically in Figure 7. The effect of temperature on the adsorption of the residues by nanoparticles based SPE cartridges was tested in the range 10 to $50^{\circ} \mathrm{C}$. After spiking, the water samples were allowed to equilibrate in temperature controlled water bath for 30 minutes. After equilibration $500 \mathrm{~mL}$ of sample solution was passed through the cartridges at the flow rate of 3 - 4 $\mathrm{mL} /$ minute. The experiment was conducted at five different temperatures viz., $10+2,20+2,30+2$, $40+2$ and $50+2^{\circ} \mathrm{C}$. The effect of temperature was presented graphically in Figure 8.

\section{RESULTS AND DISCUSSION}

\section{Description of silica nanoparticles}

The characterizations of the nanoparticles were done by the SEM, TEM and XRD. The size of silica nanoparticles 50 to $250 \mathrm{~nm}$ length. The scanning electron microscope (SEM), transmission electron microscope (TEM) and X-ray diffraction (XRD) images of silica nanoparticles were presented in Figure. 9, Figure. 10 and Figure 11. Using the XRD pattern the size of the nanoparticles were calculated by "Debye scherrer" equation Where, $D$ is the average crystalline size, $\lambda$ the $X$ - ray wavelength, â the angular line width at half maximum intensity, $\lambda$ Bragg's angle.

$$
\mathrm{D}=\frac{0.9 \lambda}{\beta \operatorname{Cos} \theta}
$$

\section{Effect of flow rate}

The effect of flow rate in pre-concentration of residues of pyrethroids was tested with nanoparticles based silica nanoparticles based SPE cartridges. The study result shows that the increase in flow rate decreases the pre-concentration efficiency of the SPE cartridges. The recovery of pyrethroids was found to be higher with the flow rates 1 to $4 \mathrm{~mL} /$ minute. The nominal flow rate for the preconcentration of pyrethroids in water was established as 3-4 $\mathrm{mL} /$ minute. The increase in flow rate $>5 \mathrm{~mL} /$ min showed decrease in recovery percentage.

\section{Sample volume - adsorption capacity}

A comparative study of nanoparticles based SPE cartridges with conventional C18 cartridges was conducted to determine the effect of silica nanoparticles based SPE cartridges against C18 cartridges. From the analysis it was observed that the silica nanoparticles based cartridges exhibited more capacity to trap the residues of herbicide when compared with the conventional $\mathrm{C} 18$ cartridges. The adsorption capacity of the $\mathrm{C} 18$ cartridges and silica nanoparticles based cartridges was reduced after passing $1000 \mathrm{~mL}$ of fortified water samples. The nominal sample volume for these two cartridges was $1000 \mathrm{~mL}$.

\section{Effect of pH}

The effect of $\mathrm{pH}$ in pre-concentration of herbicide residues was studied by adjusting $\mathrm{pH}$ of water samples using $0.1 \%$ hydrochloric acid or $0.1 \%$ sodium hydroxide solution. From the study it was observed that the nominal $\mathrm{pH}$ for the pre concentration of pyrethroids is 5 to 8 . The reduction in recovery percentage was observed at $\mathrm{pH}<5$ and $\mathrm{pH}>8$.

\section{Effect of ionic strength}

From the result it was observed that no significant change in the pre concentration capacity of residues was observed due to variation in ionic strength. The recovery of pyrethroids in silica nanoparticles based cartridges is in the range 85 to $97 \mathrm{dx} \%$. 


\section{Effect of temperature}

The study on the effect of temperature on the adsorption of residues indicated decrease in recovery of the pyrethroids at high temperature. The recoveries of the pyrethroids are found stable when conducted the studies between 10 to $40^{\circ} \mathrm{C}$. The tested concentrations were 0.01 and $0.1 \mathrm{ng} / \mathrm{mL}$. The recovery of triazine pyrethroids in silica nanoparticles based SPE cartridges were in the range 84 to $97 \%$ with milli $Q$ water equilibrated at $10+2$ and $20+2^{\circ} \mathrm{C}$; 81 to $95 \%$ at $30+2^{\circ} \mathrm{C}$ and $40+2^{\circ} \mathrm{C}$. The percentage of recovery reduced to 56 to $71 \%$ when analyzed the sample at $50+2^{\circ} \mathrm{C}$.

\section{CONCLUSIONS}

The study on applications of nanoparticles in the pre-concentration of residues of certain pyrethroids in water showed silica nanoparticles have the capacity to adsorb the residues of pyrethroids in water. The results are comparable with $\mathrm{C} 18$ cartridges. The recovery of residues was not influenced by $\mathrm{pH}$ or temperature. However extreme $\mathrm{pH}$ 's and temperatures reduces the recovery to a greater extent. The ionic strength, flow rate and sample volume has moderate impact on the recovery. The new analytical method developed for the simultaneous determination of residues of pyrethroids by GC-El/ MS has the LOD and LOQ at sub-nano gram level as evidenced by recovery study conducted in water samples. From the analysis it was concluded that the nanoparticles based SPE cartridges was found successful in the preconcentration of residues of pesticides in water. The performance of silica nanoparticles based cartridges was shown high recoveries. Thus silica nanoparticles very good option to utilize as solid support for the pre concentration of residues of environmental toxicants in water. The cartridges withstands high load of water samples to pass through for the pre-concentration of residues at trace levels which is an advantage over other conventional columns.

\section{ACKNOWLEDGEMENT}

The authors are thankful to the Dr. B. Gowtam Prasad, SVV University for keen interest to conduct the experiment.

\section{REFERENCES}

1. Fan Liu. Li-Xiong Wen.; Zhu-Zhu Li.; Wen Yu.; Hai-Yan Sun.; Jian-Feng Chen. Materials Research Bulletin. 2009, 41, 2268 - 2275.

2. Hideyuki K.; Tomohiro M.; Satoshi K.; Tohru S.; Kiyohisa O. Microchemical Journal, 2008, 88, $82-86$.

3. Ayman D.; Amjad S.; Sameer A.; Ramz, S.; Jack C N. Environ. Geochem. Health. 2007, 29, $45-50$.

4. Yingying Wena.; Ling Chena.; Jinhua Lia.; Dongyan Liua, Lingxin Chen. Trends in Analytical Chemistry. 2014, 59, 26-41.

5. Al-Degs Y S.; Al-Ghouti M A. International Journal of Environmental Analytical Chemistry. 2008, 88, 487 - 498.

6. Bashir M M.; Borossay J.; Torkos Beltran K. Microchemical Journal, 1998, 58, 31-38.
7. Maofeng D.; Yongqiang M.; Fengmao L.; Chuanfan Q.; Lijun H.; Shuren J. Chromatographia. 2009, 69, 73 - 77.

8. Gilart N.; Borrull F.; Fontanals N.; Marce R.M. Trends in environmental analytical chemistry. 2014, 1, 8-18.

9. Pyrzynska K. Sep.Purif. Rev. 2008, 37, 372389.

10. Sheikh A.; Insisi A.; Sweileh J.A. Journal of Chromatography A. 2007, 1164, 25 - 32.

11. Sybille Merkle.; Kim Karen Kleeberg.; Jan Fritsche.; Chromatography. 2015, 2(3), 293381.

12. Dong M Y, Zhao E, Qian C, Han L, Jiang S, Microchim. Acta., (2009) 165, 123128

13. Du D M.; Wang J.; Zhang J.; Ca H Tu A.; Zhang. Electrochemistry Communications. 2008, 10, 8589. 